\title{
UTILIZAÇÃO DAS TEORIAS ADMINISTRATIVAS NA PRODUÇÃO DO CONHECIMENTO SOBRE ADMINISTRAÇÃO EM ENFERMAGEM
}

\author{
Maria Auxiliadora Trevizan * \\ Isabel Amélia Costa Mendes * \\ Cristina Maria Galvão ** \\ Namiê Okino Sawada **
}

\begin{abstract}
RESUMO - Com o propósito de verificar a utilização das teorias administrativas na produção do conhecimento sobre administração em enfermagem, as autoras realizaram pesquisa na Revista Brasileira de Enfermagem englobando um período de nove anos. Os dados foram obtidos através de levantamento, leitura e quantificação dos artigos e posterior identificação da teoria administrațiva que deu suporte ao desenvolvimento dos mesmos. Verificou-se que $15,6 \%$ dos artigos publicados no período em estudo relacionaram-se à Administração em Enfermagem Os resultados indicaram que a maioria dos artigos é provenientes da Teoria Comportamental $(36,4 \%)$ e da Teoria Neoclássica $(29,5 \%)$ da Administração.
\end{abstract}

\begin{abstract}
With the objective to verify the use of administrative theories in the literature about administration in nursing, the authors reviewed articles written over a period of 9 years in the Brazilian Nursing Journal (Revista Brasileira de Enfermagem). Data have been obtained by survey, reading and quantification of articles and later identification of the administrative theories that supported the development of these articles. A total of $15.6 \%$ of the articles published during this period of study related to administration in nursing. The results indicate that most of the articles were based on the Behavioral Theory (36.4\%) and the Neoclessic Theory $(29.5 \%)$ of Administration.
\end{abstract}

\section{INTRODUÇÃO}

Procurando contribuir para a determinação das fontes que têm impulsionado a produção do conhecimento na Enfermagem, MENDES \& TREVISAN $^{4}$ analisaram as referências bibliográficas e bibliografias consultadas, citadas por autores dos artigos publicados na Revista Brasileira de Enfermagem, durante o período de 1970 a 1981. Nesta análise, que englobou 4.119 referências provenientes de 384 artigos, 414 vinculavam-se à administração. Conforme depoimento das autoras, " $10 \%$ couberam à Administração, que representa a ciência que ocupa o 3o lugar na ordem de influência para o desenvolvimento da enfermagem, perdendo apenas para as citações da própria enfermagem $(27,6 \%)$ e para a medicina $(19,6) "$ ".

Esta contribuição da administração significa que há, por parte dos autores que utilizaram referências oriundas desta ciência, o entendimento de que as atividades empreendidas na enfermagem devem ser planejadas, organizadas, dirigidas ou lideradas, coordenadas e avaliadas. Sabe-se que estas funções administrativas foram estudadas e analisadas segundo vários pontos de vista, fundamentadas em variáveis distintas tarefas, estrutura, pessoas, ambiente e tecnologia - originando assim, diferentes teorias administrativas: Teoria Clássica, Teoria da Burocracia, Teoria das Relações Humanas, Teoria Estruturalista, Teoria Neoclássica, Teoria Comportamental, Teoria dos Sistemas e Teoria da Contingência. Adotando uma postura contingencial, entendemos que todas essas teorias são válidas e por suas características oferecem diferentes contribuições, uma vez apresentam diferentes enfoques, contemplando apenas uma ou algumas daquelas cinco variáveis mencionadas. segundo CHIAVENATO", "na realidade, cada teoria administrativa surgiu como uma resposta aos problemas empresariais mais relevantes de sua época. E, neste aspecto, todas elas foram bem sucedidas ao apresentarem soluções específicas para tais problemas. De certo modo, todas as teorias administrativas são aplicáveis às situações de hoje, e o administrador precisa conhecê-las bem, para ter à sua disposição um

\footnotetext{
* Enfermeira, Livre Docente em Enfermagem, Professor A ssociado daEscola de Enfermagemde Ribeirão Preto da Universidade de SãoPaulo.

** Enfermeira, Mestre em Enfermagem. Professor Assistente da Escola de Enfermagem de Ribeirão Preto da Universidade de São Paulo.
} 
naipe de alternativa interessantes para cada situação". Evidentemente, o enfermeiro administrador não pode prescindir deste conhecimento para utilizá-lo nas diversas situações com que se defronta na enfermagem.

Nosso propósito aqui é divulgar um exercício que realizamos para averiguar a utilização das teorias administrativas na produção do conhecimento sobre administração em enfermagem, ou seja, pretendemos comunicar os resultados de uma pesquisa que realizamos na Revista Brasileira de Enfermagem, envolvendo um período aproximadamente de nove anos, com o objetivo de quantificar os artigos sobre Administração em Enfermagem e identificar as teorias administrativas que os fundamentaram.

\section{METODOLOGIA}

Os dados utilizados neste estudo foram provenientes dos artigos sobre administração em Enfermagem contidos no períodico mencionado e publicados até o ano de realização desta pesquisa. Assim sendo, como até maio de 1991 dispunha-se apenas das publicações ocorridas até 1988, incluiu-se todas aquelas publicadas até este ano. Deste modo, todos os fascículos publicados e disponíveis, foram inseridos nesta análise envolvendo o período de 1980 a 1988, exceto o de número quatro de 1986 e número três e quatro de 1988 , ainda não publicad̀os. $\mathrm{Pa}$ - ra efeito de contagem dos artigos, não foram incluídos os editoriais, os relatórios de Comissões da ABEn, os discursos e conferências.

Os dados foram obtidos através de levantamento, leitura e quantificação dos artigos e posterior identificação da teoria administrativa que deu suporte ao desenvolvimento dos mesmos.

A Revista Brasileira de Enfermagem, da Associação Brasileira de Enfermagem foi o periódico escolhido, por ser considerado o de maior circulação na enfermagem brasileira, completando já 59 anos de existência. De acordo com MENDES, TREVIZAN 4, "'a contribuição desta Revista, ao longo desses anos, à causa da enfermagem nacional, é de valor inestimável. Os profissionais responsáveis por esta revista sempre tiveram em mente a convicção de que ela precisa refletir o desenvolvimento profissional da enfermagem, portanto, sempre houve grande interesse em que as publicações fossem produzidas essencialmente por enfermeiros".

\section{RESULTADOS E DISCUSSÃO}

A distribuição dos artigos publicados na Revista Brasileira de Enfermagem (REBEn), bem como os artigos classificados na área de Administração em Enfermagem, durante o período estudado, encontram-se demonstrados na Tabela 1.

Tabela 1 - Distribuição, por ano, dos artigos publicados pela REBEn durante o período de 1980 a 1988 e sua relação com os classificados na área de Administração em Enfermagem

\begin{tabular}{l|rc|ccc}
\hline \multicolumn{3}{|c|}{ Total } & \multicolumn{3}{c}{ Artigos da REBEn } \\
\hline Ano & \multicolumn{2}{|c|}{ Administracáa em Enfermagem } \\
\hline 1980 & 41 & $(100 \%)$ & 8 & $(19,5 \%)$ \\
1981 & 29 & $(100 \%)$ & 7 & $(24,1 \%)$ \\
1982 & 16 & $(100 \%)$ & - & - \\
1983 & 28 & $(100 \%)$ & 5 & $(17,8 \%)$ \\
1984 & 37 & $(100 \%)$ & 9 & $(24,3 \%)$ \\
1985 & 41 & $(100 \%)$ & 8 & $(19,5 \%)$ \\
1986 & 27 & $(100 \%)$ & 4 & $(14,8 \%)$ \\
1987 & 38 & $(100 \%)$ & $2,6 \%)$ \\
1988 & 25 & $(100 \%)$ & 2 & $(8.0 \%)$ \\
\hline Total & 282 & $(100 \%)$ & 44 & $(15,6 \%)$ \\
\hline
\end{tabular}

De um total de 282 artigos publicados no período mencionado, $44(15,6 \%)$ relacionam-se à Administração em Enfermagem, os quais po- dem ser visualizados na Tabela 2 segundo ano de publicação e teoria administrativa utilizada. 
Tabela 2 - Distribuição dos artigos sobre Administração em Enfermagem, publicados na Revista Brasileira de Enfermagem no período de 1980 a 1988, segundo ano e teoria administrativa utilizada.

\begin{tabular}{|c|c|c|c|c|c|c|c|}
\hline \multirow[b]{2}{*}{ Ano } & \multicolumn{6}{|c|}{ Teoria } & \multirow[b]{2}{*}{ Total } \\
\hline & Clássica & Burocracia & Neoclássica & Comportamental & Sistemas & Náo Identificada & \\
\hline 1980 & 3 & - & - & 5 & - & - & 8 \\
\hline 1981 & - & - & 3 & 1 & 3 & - & 7 \\
\hline 1982 & - & - & - & - & - & - & - \\
\hline 1983 & - & - & 1 & 2 & - & 2 & 5 \\
\hline 1984 & - & 1 & 2 & 5 & - & 1 & 9 \\
\hline 1985 & 1 & - & 3 & 2 & 1 & 1 & 8 \\
\hline 1986 & - & - & 3 & 1 & - & - & 4 \\
\hline 1987 & - & 1 & - & - & - & - & 1 \\
\hline 1988 & 1 & - & 1 & - & - & - & 2 \\
\hline Total & $5(11,4 \%)$ & $2(4,5 \%)$ & $13(29,5 \%)$ & $16(36,4 \%)$ & $4(9,1 \%)$ & $4(9,1 \%)$ & $44(100,0 \%)$ \\
\hline
\end{tabular}

Dos 44 artigos classificados, $36,4 \%$ receberam suporte da Teoria Comportamental. Estes trabalhos versaram sobre os seguintes aspectos da Administração em Enfermagem:

- Administração e desenvolvimento de recursos humanos, visando o crescimento e a competência continuada do indivíduo;

- Administração da assistência ao paciente, focalizando as atividades do enfermeiro neste exercício e a administração da assistência no período-pré-operatório, em unidade de internação pediátrica e em serviços pediátricos;

- Planejamento da assistência de enfermagem em unidade de internação tendo em vista a implantação de metodologia para sistematização da assistência:

- Percepção do paciente sobre o ambiente de sua unidade;

- Funções da equipe de enfermagem a serviço da humanização;

- O papel do líder na motivação da assistência de enfermagem;

- Administração participativa de enfermagem nos serviços de saúde.

Os artigos provenientes da Teoria Neoclássica correspondem a $29,5 \%$ dos 44 que tratam da Administração em Enfermagem. A Teoria Neoclássica fundamentou a abordagem das seguintes temáticas:

- Aspectos organizacionais e administrativos da integração da assistência e do ensino de enfermagem;

- Funções e organização do trabalho do pessoal de enfermagem, tanto em serviços de saúde comunitária como na área hospitalar;

- Custos assistenciais e a enfermagem focalizando recursos financeiros, custos hospitalares e custo operacional de técnicas utilizadas;

- Supervisão e avaliação do auxiliar de saúde em programas de assistência primária;

- Análise administrativa em enfermagem;

- Política organizacional dos Serviços de
Enfermagem - modelo de administração descentralizada;

- Estruturação de programas no Serviço de Enfermagem;

- Avaliação do desempenho do enfermeiro em unidades de internação;

- Orientação de funcionários recém-admitidos em hospital.

A contribuição de Teoria Clássica se deu ao nível de $11,4 \%$ dos artigos que abordam a Administração em Enfermagem. Esta teoria embasou trabalhos sobre:

- Fadiga e condições físicas de trabalho do pessoal de enfermagem;

- Cálculo quantitativo, funções dos recursos humanos e recursos materiais para a assistência de enfermagem;

- Centralização de serviços hospitalares;

- Atividades dos enfermeiros de Centro de Material;

- A prática de enfermagem no serviço noturno.

Da Teoria dos Sistemas, cuja porcentagem de artigos é de $9,1 \%$, originaram estudos que trataram dos seguintes assuntos:

- O papel do hospital no desenvolvimento dos recursos humanos em enfermagem;

- Ações de enfermagem na equipe de saúde;

- Capacitação de recursos humanos em enfermagem;

- A ambiguiidade funcional do enfermeiro entre assistência de enfermagem e administração de serviços de enfermagem.

Em relação à Teoria da Burocracia, este estudo mostrou que ela teve uma participação bastante limitada nos artigos produzidos sobre Administração em Enfermagem; a porcentagem de artigos oriundos desta teoria é de $4,5 \%$, versando sobre:

- Utilização das folhas de controle das unidades de Terapia Intensiva;

- Função administrativa do enfermeiro no contexto da burocratização hospitalar.

Em $9,1 \%$ dos 44 artigos que se constituiram no objeto deste estudo, não foram identificadas 
teorias administrativas que fundamentassem os seguintes temas:

- Expectativas do pessoal de enfermagem em relação ao trabalho do enfermeiro;

- Administração da assistência de enfermagem;

- Implantação do programa de saúde por enfermeiro;

- A Política Organizacional de serviços de enfermagem.

Em tais artigos seus autores não deixaram evidências de que tinham um quadro teórico de referência, à luz do qual o estudo tenha sido conduzido.

Durante o período pesquisado não foi identificado nenhum trabalho derivado das Teorias das Relações Humanas, Estruturalista e Contingencial.

Para a elaboração dos 44 artigos classificados, foram envolvidos 93 autores; cuja atuação profissional e teoria utilizada, encontram-se indicadas na Tabela 3.

Tabela 3 - Distribuição dos autores dos artigos de Administração em Enfermagem, publicados pela REBEn, de 1980 a 1988, segundo teoria utilizada e atuação profissional.

\begin{tabular}{l|c|c|c|c|c|c|c}
\hline Autores & clássica & $\begin{array}{c}\text { Buro- } \\
\text { cracia }\end{array}$ & $\begin{array}{c}\text { Neo- } \\
\text { clássica }\end{array}$ & $\begin{array}{c}\text { Comporta- } \\
\text { mental }\end{array}$ & Sistemas & $\begin{array}{c}\text { Não identi- } \\
\text { ficadas }\end{array}$ & $\begin{array}{c}\text { Total } \\
\text { Enfermeiro Docente }\end{array}$ \\
Enfermeiro Docentel & - & 4 & 14 & 21 & 4 & 3 & 49 \\
Assistencial & - & - & 1 & 6 & - & 1 & 8 \\
Enfermeiro Assistencial & 4 & - & 6 & 16 & 1 & 4 & 31 \\
Alunos Enfermagem & 3 & - & - & - & - & - & 3 \\
Atuação Não-Identificada & - & - & 2 & - & - & - & 2 \\
\hline Total & 10 & 4 & 23 & 43 & 5 & 8 & 93 \\
\hline
\end{tabular}

Esta Tabela demonstra que $46,2 \%$ dos autores têm fundamentado seus trabalhos na Teoria Comportamental e $24,7 \%$ na Teoria Neoclássica.

Ao analisar a evolução da teoria administrativa, KWASNICKA ${ }^{3}$ afirma que estudos e teorias em ciências do comportamento e pesquisa operacional têm aumentado nos últimos 20 anos e afetado profundamente a prática administrativa e de tomada de decisão.

A Teoria Comportamental pauta-se em processos democráticos para a solução de problemas organizacionais, apoiando-se na conduta das pessoas, para explicar o comportamento da organização. Os comportamentalistas fundamentam-se na teoria da decisão para explicar o comportamento humano nas organizações, onde cada indivíduo tem participação consistente e racional na tomada de decisões individuais, entre alternativas mais ou menos racionais, em função de sua personalidade, motivações, atitudes e de sua percepção da situação.

Segundo KWASNICKA ${ }^{3}$, a pesquisa operacional é o veículo através do qual os objetivos da administração são atingidos, pelo uso da estatística, da matemática e da lógica para estruturar e resolver um problema. "A pesquisa operacional é a maior contribuição das teorias matemáticas à ciência administrativa e está diretamente ligada ao processo decisório . ..."3. De acordo com CHIAVENATO", "uma das mais marcantes contribuições desta abordagem foi a conscientização sobre a necessidade de colo- cação de objetivos, recursos, restrições e riscos".

Explicitamos estas características da pesquisa operacional, por se alinharem dentro da orientação neoclássica. Aliás, alguns autores denominam a Teoria Neoclássica de Escola Operacional ou Escola do Processo Administrativo. Portanto, podemos entender que, estudos nas áreas comportamental e neoclássica têm tido uma grande expansão e assim influenciado outras áreas da atividade humana.

Neste estudo, como já mencionamos, $36,4 \%$ dos artigos sobre Administração em Enfermagem são provenientes da Teoria Comportamental e $29,5 \%$ da Neoclássica, caracterizando a maior utilização das mesmas para a produção do conhecimento nessa linha de pesquisa; por conseguinte, podemos inferir que essas duas teorias têm também influenciado a prática administrativa de enfermagem.

$\mathrm{Da}$ análise destes resultados depreende-se que a Enfermagem tem incorporado da Teoria Comportamental da Administração, pelo menos a nível teórico, a aplicação de seus conceitos relativos à administração da assistência ao paciente, bem como ao desenvolvimento de recursos humanos em sua amplitude maior, nas dimensões de pessoa e profissional.

$\mathrm{Da}$ Teoria Neoclássica, a Enfermagem tem absorvido conceitos que têm fundamentado sua ação administrativa, no que tange a funções e organização do trabalho, recursos financeiros e custo operacional de serviços prestados, ava- 
liação de desempenho e administração descentralizada, dentre outros.

\section{CONSIDERAÇŌES FINAIS}

Tratando da Administração como profissão e compromisso, DRUCKER ${ }^{2}$ salienta que em uma sociedade composta de organizações, o conhecimento da administração e a competência no seu exercício são fundamentais, uma vez que proporcionam a compreensão e o controle.

Procuramos neste estudo averiguar a utilização das teorias administrativas na produção do conhecimento sobre administração em enfermagem, ou seja, procuramos verificar o conhecimento que a Enfermagem tem adquirido da Administração.
Num período aproximado de nove anos, $15,6 \%$ dos artigos publicados na REBEn demonstram que os enfermeiros têm incorporado conhecimento sobre administração. Mas administração não é só conhecimento. Administração é trabalho, é exercício. "Administrar significa assumir tarefas. Significa disciplina. Mas significa tamberm gente"' 2 . Evidentemente, o conhecimento é imprescindível para o exercício. Eficácia depende de compreensão dos conceitos de Administração. Neste sentido, acreditamos que os enfermeiros que utilizaram as teorias administrativas, sobretudo aqueles que se apoiaram nas Teorias Comportamental e Neoclássica estão assim compreendendo a Administração e conseqüentemente sua aplicação à Enfermagem.

\section{REFERÊNCIAS BIBLIOGRÁFICAS}

1 CHIA VENA TO, I. - Teoria Geral da Administração. $3^{\text {a }}$ ed., São Paulo: Mac graw-Hill, vol. 1, 1987.

2 DRUCKER, P.F. - Introdução à Administração. - Trad. Carlos A. Malferrari, São Paulo: Pioneira, 1984.

3 KWASNICKA, E.L. - Introdução à Administração, 4" ed.,
São Paulo: Atlas, 1990.

4 MENDES, I.A.C., TREVISAN, M.A. - As fontes do conhecimento $e$ as tendências subjacentes nos artigos publicados na Revista Brasileira de Enfermagem de 1970 a 1981. Rev. Bras. Enf., RS, 36(2): 154-163, 1983.

NAO FIQUE APENAS SÓCIO, PROCURE A ABEn DO SEU ESTADO 